\title{
建筑施工中混凝土浇筑技术的应用
}

\author{
张 涛 \\ 陕西航天建设集团有限公司，陕西西安 710016
}

\begin{abstract}
[摘要] 混凝土是现代施工使用的最多的一种建筑材料, 在工程建设中的应用是非常广泛的, 而因为其重要性混凝土浇筑技术 也在不断的发展。如今建筑工程的规模正在变得越来越大, 这也导致混凝土浇筑的施工难度不断提升, 由此也产生了各种各 样的问题, 比如说混凝土浇筑以后形成的贯穿裂缝以及非结构性裂缝等等。这两种问题对建筑工程质量的影响非常大, 同时 后期的修复难度也颇高, 不仅增加了建筑工程的维护成本, 同时也难以保证建筑本身的安全性。因此, 在混凝土浇筑技术使 用的过程中, 需要在细节层面对混凝土技术进行全方位的优化, 进而使混凝土浇筑技术成为推动建筑行业不断发展的重要动 力。
\end{abstract}

[关键词]建筑施工; 混凝土; 浇筑技术; 应用

DOI: $10.33142 /$ aem.v2i4.2001 中图分类号: TU755.6 文献标识码: A

\section{Application of Concrete Pouring Technology in Building Construction}

ZHANG Tao

Shaanxi Aerospace Construction Group Co., Ltd., Xi'an, Shaanxi, 710016, China

\begin{abstract}
Concrete is the most widely used building material in modern construction, which is widely used in engineering construction. Because of its importance, concrete pouring technology is also developing. Nowadays, the scale of construction engineering is becoming larger and larger, which also leads to the increasing difficulty of concrete pouring construction, which also produces a variety of problems, such as through cracks and non structural cracks formed after concrete pouring and so on. These two kinds of problems have a great influence on the quality of construction projects. At the same time, the later repair is very difficult, which not only increases the maintenance cost of construction projects, but also can not guarantee the safety of the building itself. Therefore, in the process of using the concrete pouring technology, it is necessary to optimize the concrete technology in all aspects at the detail level, so as to make the concrete pouring technology become an important driving force to promote the continuous development of the construction industry.
\end{abstract}

Keywords: building construction; concrete; pouring technology; application

引言

混凝土浇筑的实践性是很强的, 必须要符合建筑项目的特征和实际的施工情况, 在应用的过程中必须要选择好合 适的浇筑技术, 进行规范的作业这样才能使混凝土结构变得更加的稳固。

1 混凝土浇筑技术在现代建筑行业中的发展状况

(1) 混凝土是由多种原材料拌合而成的, 包括水泥、砂石料以及水等, 还有就是其他的一些特殊添加剂, 是建筑 施工常用的一种材料。利用的是水泥的水化反应, 在混凝土凝固以后它的强度就会变得很大, 在建筑行业当中具有不 可替代性。混凝土的强度和韧性与原材料之间的拌和状况有着直接关系, 因此, 在现代建筑工程中, 人们越来越重视 混凝土原材料的拌和比, 混凝土的质量也在这种发展趋势中得到了实质性的提升。混凝土浇筑是建筑施工中非常重要 的一项施工技术, 而混凝土的浇筑容易受到各种因素的影响, 导致其出现各种各样的问题 ${ }^{[1]}$ 。其中最重要的一个因素 就是混凝土结构内外的温度差, 因为温度差的影响会使其内部结构产生应力, 形成的裂缝就会达到结构的表面, 在表 面就会形成裂缝，如果出现了这样的裂缝结构又受到比较大的力的作用的话就有断裂的可能。

(2) 热胀冷缩现象对于混凝土的影响也是很大的, 混凝土浇筑以后, 它的热量就会快速的散发出来, 这样混凝土 内部的温度就会不断下降, 这时候浇筑的接触位置就会形成拉应力, 那么, 当其超过混凝土的抗拉性的时候就很可能 产生贯穿性裂缝。这种裂缝会对建筑产生很大的影响, 有时候更是会引发安全事故。所以对于混凝土浇筑技术的研究 重点就在于裂缝的防范上, 应该通过更加科学的手段尽量的防止出现这样的问题 ${ }^{[2]}$ 。

\section{2 混凝土浇筑技术的应用}

2.1 前期准备工作

混凝土是由多种原材料配置而成的，这些原材料的质量会直接对混凝土浇筑技术的应用效果产生很大的影响。所 
以, 必须要保证这些原材料的质量符合相应的标准与要求。为了控制好原材料的质量, 首先就是对原材料采购环节的 控制, 在进行采购的时候必须要严格的检测这些材料的品质, 材料在进入现场以后要进行妥善的管理同时还要定期进 行抽样检测, 通过这样的方式来保证这些原材料的质量, 为混凝土质量控制提供保障。对于混凝土浇筑质量会产生影 响的还有混凝土的拌合, 这一环节的影响也是很大的, 其中最重要的就是对于配合比的控制, 其次就是拌合过程的规 范性 ${ }^{[3]}$ 。结合实际情况对骨料和添加剂的填入顺序进行合理的安排, 并且要计算出拌合的时长以及拌合的力度。其次, 各种不同类型的混凝土物料在性质方面是存在明显的差别的, 所以在进行混凝土配置工作的过程中, 务必要对工程的 需求进行综合分析, 从而保证混凝土的质量能够满足实际的需要。最后, 混凝土的运输过程中管理与混凝土的质量存 在密切的关联, 当下建筑工程行业为了保证混凝土的质量, 往往都会选择运输葲来进行混凝土的运送工作, 这样可以 更好的保障混凝土的质量以及运输效率, 减少运输可能对混凝土带来的不良影响。在使用运输设备的时候工作人员必 须要严格的对其进行检查，确保其状态良好，保证运输设备的性能后再进行后续的运输工作。

\section{2 施工设计重点}

第一点就是要先准备好施工所需的各种装备以及工具, 比如说斗车、铁锹、振捣器以及振捣棒等, 这些都要根据 项目的具体要求还是现场的实际情况来进行选择, 必须要符合相关的施工标准以及规程, 如此才能为混凝土浇筑施工 的顺利展开打好基础，保证作业的质量，不会因为不合格而出现返工的问题 ${ }^{[4]}$ 。

\section{3 合理选择施工材料}

混凝土是由水泥、砂石料还有水以及其它的一些添加剂拌合而成的，这些材料的质量、规格、型号以及比例等等 都会对混凝土的性能产生很大的影响。一般来说拌制好的混凝土在凝固以后是非常的坚固的, 刚度是很高的, 受压能 力非常的强。不过, 混凝土也有一定的缺点就是受拉能力不强, 在受到外力作用的时候有可能会断裂, 这对其应用也 产生了很大的影响, 所以, 为了提升它的受压能力、抗拉能力都会在混凝土结构中加入钢筋, 在两者凝固而形成一个 整体以后其承受外力作用的能力就会变得非常强, 这这就是我们所说的钢筋混凝土。在进行混凝土浇筑之前需要对现 场的气温、天气以及环境等进行全面的考察, 根据现场的情况、工程的需求对混凝土的配置比例进行科学的设计, 确 保其性能能够满足各方面的要求 ${ }^{[5]}$ 。

\section{4 钢筋绑扎施工技术}

钢筋的绑扎通常都是在进行混凝土浇筑之前就要完成的, 这道工序的具体步骤为: 一, 先将坚向的受力筋按照施 工设计的要求按照规定的方式连接起来; 二, 根据设计图纸对立柱中坚向的钢筋把筢筋间距线划出来; 三, 套柱筷筋, 要按照设计图纸对于间距的要求计算每根柱筷筋需要有多少根, 首先用䈨筋把下层的搭接筋套上, 之后就是树立柱子 钢筋, 在搭接的位置要有三个以上的绑扣, 且绑扣都必须是向着柱中心的。

\section{5 模板搭建和施工技术的组合}

对于建筑工程的建设来说比较常用的模板搭接以及施工技术就是大模板施工技术、飞模施工技术、爬升模板施工 技术、胶合板模板施工技术、永久性模板施工技术以及组合钢模板施工技术等等, 他们有着各自的特点, 有着不同的 适用范围，可以满足各种不同施工项目的使用需求。

\section{6 钢筋混凝土结构施工技术}

这类的施工技术比较常用的就是斜面分层、分段分层，还有全面分层等几种浇筑技术。

\section{7 浇筑完成后的养护工作}

在结束了混凝土浇筑之后还要进行科学、合理的养护, 这对于混凝土的施工质量也是有着很大的影响的, 制定科 学的养护方案并落实好不能可以降低维护的成本, 还可以避免混凝土出现其他的一些问题, 提高混凝土结构的质量。 养护工作最重要的一点就是对于混凝土温度的控制, 以此来对混凝土内外的温差进行控制, 防止因为温差过大导致混 凝土结构出现裂缝。混凝土的养护还可以采用为混凝土构件覆盖草窝或者麻片的方式为混凝土保温和保湿, 防止其温 度下降过快，保持其表面的湿润性。整个养护时间应在 $12 \mathrm{~h}$ 以上，使养护工作发挥其最大的效用。

\section{结束语}

综上所述, 建筑工程中的混凝土浇筑是一项综合性的工程, 若想保证浇筑质量, 就需要对混凝土浇筑的全过程进 行控制管理，保证浇筑工作的质量和效率，从而使建筑工程的整体质量得到实质性的提高。

\section{[参考文献]}

[1]李瑞华.混凝土浇筑施工技术在建筑工程施工中的应用 $[\mathrm{J}]$. 居舍, 2020,8 (11): 31.

[2]张哲宁. 建筑施工中混凝土浇筑技术的应用 [J]. 建材与装饰, 2020, 9 (10): 24-25.

[3] 赵子斌.混凝土浇筑施工技术在建筑工程施工中的应用研究 [J]. 建材与装饰, 2019, 9(35): 38-39.

[4]杨永宏.混凝土浇筑技术在建筑施工中的研究 [J].智能城市, 2019, 5 (22) : 135-136.

[5]李桂靖.混凝土浇筑施工技术在建筑工程施工中的应用 [J]. 地产, 2019, 9 (21) : 106-107.

作者简介: 张涛 (1980.5-), 男, 毕业于西安长安大学, 工民建专业, 陕西航天建设集团有限公司, 项目经理, 现有 职称：工程师。 